\title{
Pressure effect on rate of production of glucose-equivalent in plant cells
}

\author{
ANIRBAN PANDA, SURJENDU BHATTACHARYYA and SAMBHU N DATTA* \\ Department of Chemistry, Indian Institute of Technology Bombay, Powai, Mumbai 400076 \\ e-mail: sndatta@chem.iitb.ac.in
}

MS received 2 January 2009; accepted 8 April 2009

\begin{abstract}
The rate of glucose equivalent production in $\mathrm{C}_{4}$ green plants is investigated as a function of the intercellular partial pressure of $\mathrm{CO}_{2}$, so as to find the precise physical chemistry of photosynthesis. Expressions are first formulated for the dependence of photochemical efficiency and of rubisco activation on pressure. Then a pressure-dependent rate law is derived. The latter is successfully tested for two specific $\mathrm{C}_{4}$ plants, namely, Panicum antidotale and Panicum coloratum.
\end{abstract}

Keywords. $\mathrm{C}_{4}$ Green plants; rate of equivalent production; pressure effect.

\section{Introduction}

Research on green plant photosynthesis has gained a tremendous momentum for several decades. ${ }^{1-4}$ The group of $\mathrm{C}_{4}$ plants constitutes a major part of plant population, and several experimental studies have been performed on them. ${ }^{2}$ An extensive amount of research has been carried out on the effect of intensity of light, the duration of exposure to sun rays, temperature, $\mathrm{CO}_{2}$ pressure, and stomatal conductance. ${ }^{1,3}$ Ghannoum et al investigated the photosynthetic mechanism of young $\mathrm{C}_{4}$ leaves and showed its differences with $\mathrm{C}_{3}$-photosynthetic mechanism. ${ }^{2 \mathrm{~b}}$ Crafts-Brandner and Salvucci analysed the impact of high temperature and $\mathrm{CO}_{2}$ internal pressure on the net rate of photosynthesis. ${ }^{3 i}$ Research has also been conducted on the activity of the enzymes involved in the photosynthetic process, especially on the activation and competitive inhibition processes of the enzyme 1,5-ribulose biphosphate carboxylase/oxygenase (rubisco). ${ }^{1 \mathrm{~d}, 3}$ Rubisco is the most influential enzyme of the whole process as it catalyses the conversion of $\mathrm{CO}_{2}$ to 3PGA. Farquhar carried out a modelling investigation to determine the kinetic properties of Rubisco and the dependence of electron transport on photon flux. ${ }^{4}$ Harley et al modified this model so that the parameters used could be established from whole-leaf gas-exchange measurements. ${ }^{5}$ The latter authors also combined this model with the equations

\footnotetext{
*For correspondence
}

developed by Tenhunen et $a l^{6}$ to investigate the interactive effects of the incident irradiance, leaf temperature, and partial pressures of $\mathrm{CO}_{2}$ and $\mathrm{O}_{2}$. The behaviour of photosynthetic enzyme under elevated $\mathrm{CO}_{2}$ pressure was experimentally investigated by $\mathrm{Vu}$ et $a l^{7}{ }^{7}$ Portis et al examined the activation of rubisco at physiological $\mathrm{CO}_{2}$ concentration by another enzyme, called rubisco activase. ${ }^{8 a}$ Cen et al demonstrated the regulation of the rubisco activity in response to variation in ambient $\mathrm{CO}_{2}$ pressure and leaf temperature ${ }^{8 \mathrm{~b}}$ In fact, the $\mathrm{CO}_{2}$ assimilation rate as function of the intercellular $\mathrm{CO}_{2}$ pressure has been measured. ${ }^{2}$ Despite these advances, a quantitative expression for the dependence of the rate of glucose-equivalent production on the intercellular $\mathrm{CO}_{2}$ partial pressure is lacking in literature.

Recently, we have formulated an integrated rate equation for the production of glucose-equivalents in $\mathrm{C}_{4}$ green plants under the condition of a high and constant partial pressure of $\mathrm{CO}_{2}$ in chloroplast. ${ }^{9 a} \mathrm{We}$ use the term glucose-equivalent for photosynthates like sucrose, starch, etc., which produce glucose in the plant cell by self-degradation. The rate equation was established by considering the so-called photochemical reactions (light reactions) and biosynthetic reactions (dark reactions) of photosynthesis in green plants. In a subsequent paper, ${ }^{9 \mathrm{~b}}$ the validity of the rate expression was examined for five specific $\mathrm{C}_{4}$ plants.

In the present work, we have theoretically investigated the dependence of the rate of glucose- 
equivalent production on the intercellular $\mathrm{CO}_{2}$ partial pressure $\left(p_{\mathrm{CO}_{2}}\right)$ in $\mathrm{C}_{4}$ plants. To the best of our knowledge, this is the first effort in this direction. We specifically show that the reaction sequence due to King and Altman ${ }^{10}$ and Farquhar, ${ }^{1 \mathrm{j}}$ along with the steps of competitive inhibition of the inactive form of the enzyme and denaturation of the active form, can successfully explain the pressure-dependence of glucose-equivalent production. We have organized the present paper in the following way. Modifications of the rate equation have been described in section 2, and the photochemical efficiency is discussed in section 3 . Section 4 deals with the effect of pressure on enzyme activity. In section 5, results of our formulation have been discussed for two specific plants, and a summary of our conclusions has been given in the last section.

\section{Rate equation}

The reaction sequence of photosynthesis including both the light reactions and the dark reactions is extraordinarily complicated. Many of these steps are co-regulatory, and it is always better to use a systems approach including all known steps of reasonable kinetic behavior. ${ }^{11}$ One should also consider the regulation of the light reactions via the so-called non-photochemical quenching as well as through the lumen $\mathrm{pH}$-driven regulation at the level of cytochrome-b6f complex. In fact, Laisk and Edwards constructed a numerical model of $\mathrm{C}_{4}$ photosynthesis considering all enzymatic reactions and most of the regulatory functions. ${ }^{12}$ Their model provides good simulations for various rates of intermediate steps under varying light intensity and concentrations of $\mathrm{CO}_{2}$ and $\mathrm{O}_{2}$. It also relates production rate of NADPH with that of ATP. However, this strategy makes the whole formulation very complicated, to be tracked only numerically, and a physical understanding of the integrated process is invariably lost.

The plant cell being a highly compartmentalized system, the application of any arbitrary treatment like chemical kinetics in a solution is not appropriate. A conceptual understanding is obtained when we rely on experimental methodologies like apparent equilibrium treatments and steady state approximations, and group the entire photosynthetic process into only a few classes of reactions. Therefore, in our previous work, we simplified the whole reaction sequence into seven groups of reactions. ${ }^{9}$ This is also the basis of the present work.
In our previous derivation of the integrated rate expression for $\mathrm{C}_{4}$ plants, ${ }^{9 \mathrm{a}, \mathrm{b}}$ it was assumed that these plants are not under any environmental stress and the intercellular partial pressure of $\mathrm{CO}_{2}$ is high. Thus the effect of any change of $\mathrm{CO}_{2}$ partial pressure on the glucose equivalent production rate was not considered. Recent studies on $\mathrm{C}_{4}$ photosynthesis show that the rate of $\mathrm{CO}_{2}$ assimilation $\left(A_{\mathrm{CO}_{2}}\right)$ as well as photochemical efficiency $(\phi)$ increase with intracellular $\mathrm{CO}_{2}$ concentration that is dependent on the intercellular $\mathrm{CO}_{2}$ partial pressure. ${ }^{3,7}$ Following the treatment in references by Mehta et al, ${ }^{9 \mathrm{a}, \mathrm{b}}$ the rate of production of glucose-equivalent is written as

$$
\begin{aligned}
R_{\text {glucose }}= & (8 / 3) R_{1}^{\prime} v_{L} \phi(T, p) g(T, p) \\
& \left([\mathrm{G} 3 \mathrm{P}] /\left[\mathrm{P}_{\mathrm{i}}\right]^{2}\right)_{\text {leaf }} Q_{\mathrm{G} 3 \mathrm{P} \rightarrow \text { Glc-6-P }} \times \mathrm{PPFD},
\end{aligned}
$$

where $R_{1}^{\prime}$ is the theoretically calculated rate of NADPH production in mol ( $\mathrm{L}$ of lumen $)^{-1} \mathrm{~s}^{-1}$ given by $R_{1}^{\prime}=3.235 \times 10^{-7}\left[672 \cdot 5-197 \cdot 3 \mathrm{e}^{-(1 \cdot 795+0.000462 \mathrm{~T})}\right],{ }^{9 \mathrm{c}}$ $v_{L}$ is the lumen volume in $\mathrm{L}$ per $\mathrm{m}^{2}$ of leaf area, $\phi(T, p)$ is the photochemical efficiency, $g(T, p)$ is the enzyme activation quotient, $[\mathrm{G} 3 \mathrm{P}]$ and $\left[\mathrm{P}_{\mathrm{i}}\right]$ are the global concentrations of glyceraldehydes-3phosphate and inorganic phosphates inside the leaf, $Q$ is the concentration reaction quotient for the overall conversion of G3P into Glc-6- $\mathrm{P}^{2-}$, and PPFD is the photosynthetic photon flux density.

The modifications required here involve treating $\phi$ and $g$ in (1) as functions of not only temperature but also pressure.

\section{Photochemical efficiency}

The $\mathrm{CO}_{2}$ leaf concentration can be expressed as

$$
\left[\mathrm{CO}_{2}(\mathrm{BS})\right]=\left[\mathrm{CO}_{2}(\mathrm{BS})\right]_{\mathrm{sat}} \widetilde{P}_{\mathrm{sat}}\left(T, p_{\mathrm{CO}_{2}}\right),
$$

where $\left[\mathrm{CO}_{2}(\mathrm{BS})\right]_{\text {sat }}$ is the limiting value of the concentration of $\mathrm{CO}_{2}$ in the bundle sheath, and $\widetilde{P}_{\text {sat }}\left(T, p_{\mathrm{CO}_{2}}\right)$ is the saturation probability at a particular temperature $T$ and a specific $\mathrm{CO}_{2}$ partial pressure $p_{\mathrm{CO}_{2}}$. Because $T$ and $p_{\mathrm{CO}_{2}}$ are two independent quantities, to the lowest order $\widetilde{P}_{\text {sat }}$ can be expressed as a multiplicative function

$$
\widetilde{P}_{\text {sat }}(T, p)=P_{\text {sat }}(T) f(p) .
$$

It is known that the photochemical efficiency for the $\mathrm{C}_{4}$ plants rises very sharply with pressure and ulti- 
mately reaches a constant value at the high pressure limit. ${ }^{13}$ In the high pressure limit, the probability $f(p)$ should be unity, and

$$
\widetilde{P}_{\text {sat }}\left(T, p_{\mathrm{CO}_{2}}^{\text {high }}\right)=P_{\text {sat }}(T),
$$

which was the condition used in our previous work. ${ }^{9 a, b}$ It was also shown that with time the NADPH concentration gradually builds up from an initial zero value and ultimately reaches a saturation value. The variation of NADPH concentration with time is given $b y^{9 a, b}$

$$
[\mathrm{NADPH}](t)=\sqrt{\frac{R_{1}}{b}} \frac{e^{2 \sqrt{R_{1} b}}-1}{e^{2 \sqrt{R_{1} b}}+1},
$$

where $R_{1}$ is the net rate of production of NADPH in chloroplast, ${ }^{9 a}$ a product of the maximum possible NADPH production rate $\left(R_{1}^{\prime}\right)$ and the survival probability of the membrane. Besides, $b$ is given by

$$
b=2 k_{3}^{\text {eff }}\left[\mathrm{CO}_{2}(\mathrm{BS})\right]+3 k_{3}^{\text {eff }}\left[\mathrm{CO}_{2}(\mathrm{BS})\right]_{\mathrm{sat}} .
$$

In the above $k_{3}^{\text {eff }}$ is the effective rate constant for the ultimate conversion of $\mathrm{CO}_{2}(\mathrm{BS})$ to Glyceraldehyde-3-phosphate (G3P).

Using (2) in (6) we get

$$
b=k_{3}^{\mathrm{eff}}\left[\mathrm{CO}_{2}(\mathrm{BS})\right]\left[2+\frac{3}{\tilde{P}_{\mathrm{sat}}(T, p)}\right] .
$$

The importance of this relationship is discussed in the following. The photochemical efficiency $(\phi)$ is defined as the ratio of the number of $\mathrm{CO}_{2}(\mathrm{BS})$ used up and the number of photons consumed. Considering the membrane survival probability $P_{\text {mem }}(T)$, we get $^{9}$

$\phi=\frac{1}{8}\left(\frac{\text { Rate of production of G3P }}{\text { Rate of production of NADPH }}\right) \times P_{\text {mem }}(T)$,

where $P_{\text {mem }}(T)$ varies in the range $0 \leq P_{\text {mem }}(T) \leq 1$ from the high temperature to a moderate temperature. The rate of production of G3P $\left(2 R_{3}\right)$ is given by

$$
2 R_{3}=\frac{2 \widetilde{P}_{\text {sat }}(T, p)}{2 \widetilde{P}_{\text {sat }}(T, p)+3} R_{1}
$$

Therefore, $\phi$ can be written as

$$
\phi=\frac{1}{4}\left(\frac{\widetilde{P}_{\mathrm{sat}}(T, p)}{2 \widetilde{P}_{\mathrm{sat}}(T, p)+3}\right) .
$$

The factor $1 / 4$ comes from the consideration that 4 photons are required to produce 1 molecule of NADPH. ${ }^{13}$

From the experimental data, it is evident that as $p_{\mathrm{CO}_{2}} \rightarrow 0, \quad \phi \rightarrow 0$, that is, $f(p)=\tilde{P}_{\text {sat }}(T, p) /$ $\tilde{P}_{\text {sat }}(T, \infty) \rightarrow 0$. The variation of $f(p)$ with $p$ can be predicted as

$$
\mathrm{d} f(p) / \mathrm{d} p=2 \gamma(1-f) p,
$$

that is first order with respect to $(1-f)$ and first order with respect to $p_{\mathrm{CO}_{2}}$. This yields the solution $f(p)=1-\exp \left(-\gamma p^{2}\right)$. Therefore, we have chosen a function of the form $f_{n}=1-\exp \left(-\gamma p^{n}\right)$ and compared with the experimental efficiency curve by a least square fitting. The theoretically determined curve along with the experimental curve of $\phi$ versus $p_{\mathrm{CO}_{2}}$ is shown in figure 1. The experimental points have been taken for an average $\mathrm{C}_{4}$ plant. ${ }^{13}$ The least square analysis yields $n=1.98$ and $\gamma=0.169$ as the best parameters. Obviously, $n$ is more or less equal to 2 .

Although a formulation is given here for the photochemical efficiency, the parametrized expression for $\phi$ is not used in our treatment while determining the glucose-equivalent production rate. Instead, we have relied on the experimental photochemical efficiency data. The merit of this discussion is that it lends credence to the use of $\tilde{P}_{\text {sat }}(T, p)$ as a multiplicative function, as in (3).

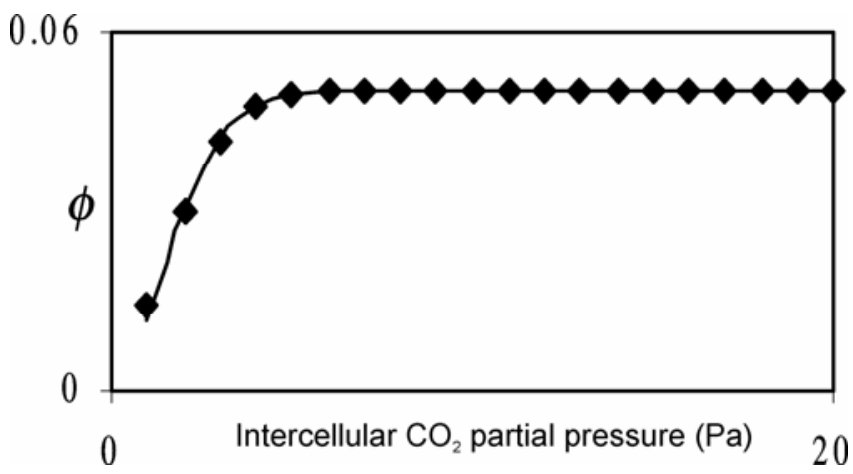

Figure 1. Average photosynthetic efficiency $(\phi)$ versus intercellular $\mathrm{CO}_{2}$ partial pressure curve. Solid line shows the theoretically determined plot with $n=2$ and $\gamma=0 \cdot 169$ and dots represent the experimental data points. Here we take $T=303 \cdot 15 \mathrm{~K}$ and $P_{\text {sat }}(303 \cdot 15)=1$. 


\section{Pressure effect}

The $\mathrm{CO}_{2}$ concentration plays a vital role on the activation of enzyme rubisco. Mate et al have showed that the carboxylation of Lys-residue within rubisco's catalytic sites takes place before carboxylation of RuBP. ${ }^{7 \mathrm{c}}$ This actually activates rubisco by allowing the binding of $\mathrm{Mg}^{2+}$. In vivo, this process of activation and maintenance of rubisco in active form is facilitated by a second enzyme called rubisco-activase. The activity of rubisco-activase is pressure dependent. Therefore, the enzyme activity quotient must be expressed as a function $g(T, p)$ that depends on both temperature and $\mathrm{CO}_{2}$ pressure.

\subsection{Activation quotient}

To determine the functional form of $g(T, p)$, the detailed mechanism of the rubisco activation process has been considered. The reaction sequence can be represented by following the methods of King and Altman ${ }^{10}$ and Farquhar. ${ }^{1 \mathrm{f}}$ This is written as

$$
\begin{aligned}
& E^{\text {inact }}+\mathrm{CO}_{2} \rightleftharpoons E \mathrm{CO}_{2} \quad\left(K_{1}\right) \\
& \mathrm{ECO}_{2}+\mathrm{Mg}^{2+} \rightleftharpoons E^{\mathrm{act}} \quad\left(K_{2}\right),
\end{aligned}
$$

where $E^{\text {inact }}$ is the inactive form of the enzyme, $\mathrm{ECO}_{2}$ is an intermediate and $E^{\text {act }}$ is the activated form of the enzyme, and $K_{1}$ and $K_{2}$ are the two equilibrium constants. This mechanism is generally valid for all higher plants.

It is well-known that the enzymatic reaction is inhibited by oxygen or other molecules. The competitive inhibition can be described as

$$
E^{\text {inact }}+\mathrm{O} \rightleftharpoons E \mathrm{O} \quad\left(K_{3}\right) .
$$

To represent the denaturation of the activated enzyme, we write another additional step,

$$
E^{\mathrm{act}}+m \mathrm{CO}_{2} \rightleftharpoons E^{\mathrm{den}} \quad\left(K_{4}\right),
$$

where $K_{4}$ is the corresponding equilibrium constant. The number $m$ can vary as $0,1,2, \ldots$ The third and fourth steps may or may not be necessary. Later it is shown that only with these additional steps and the specific value of $m=1$ the observed data can be best explained.
It is well established that carbon assimilation in the bundle sheath cells of $\mathrm{C}_{4}$ plants are solely controlled by the flux of $\mathrm{CO}_{2} \cdot{ }^{14}$ However, in presence of carbonic anhydrase the assimilated $\mathrm{CO}_{2}$ sets up a rapid equilibrium with the existing bicarbonate pool. It is also known that $\mathrm{HCO}_{3}^{-}$is easily permeable to BS cells, but it can not penetrate chloroplast at significant rates. ${ }^{15}$ Even if it enters into the chloroplast it does not take part in carbon assimilation. This shows that we have an equilibrium like

$$
\begin{aligned}
& \mathrm{CO}_{2}(\text { meso })+\mathrm{H}^{+}+\mathrm{H}_{2} \mathrm{O} \stackrel{\text { Carbonic anhydrase }}{\rightleftharpoons} \\
& \mathrm{HCO}_{3}^{-} \text {(meso) } \\
& \mathrm{HCO}_{3}^{-}(\text {meso }) \stackrel{\text { Series of reaction }}{\rightleftharpoons} \mathrm{HCO}_{3}^{-}(\mathrm{BS}) \\
& \stackrel{\text { Carbonic anhydrase }}{\rightleftharpoons} \mathrm{CO}_{2}(\mathrm{BS})+\mathrm{H}^{+}+\mathrm{H}_{2} \mathrm{O} .
\end{aligned}
$$

The lack of experimental procedure to determine the level of $\mathrm{CO}_{2}$ in each compartment of leaf invokes one to carry out modelling work to determine the inorganic carbon pools in the leaves. ${ }^{14}$ However, the models reported so far determine fluxes of carbon empirically and are unable to take detailed account of intracellular $\mathrm{CO}_{2}$ distribution. In addition, the $p \mathrm{H}$ and the permeability of bicarbonate also affect the size and composition of such inorganic carbon pools. The situation becomes more complicated due to the uneven distribution of carbonic anhydrase in different locations and different compartments. Therefore, one is left only with the consideration that in the steady state, the intracellular solvated $\mathrm{CO}_{2}$ is in a constant proportion with the intercellular $\mathrm{CO}_{2}(g)$. Hence one can write the intracellular $\mathrm{CO}_{2}$ concentration as

$$
\left[\mathrm{CO}_{2}\right]=\xi p_{\mathrm{CO}_{2}},
$$

where $\xi$ is a proportionality constant. Solving (12)(15) and (17), we get

$$
g(T, p)=\frac{\left[E^{\mathrm{act}}\right]}{[E]}=\frac{p}{a+b p+c p^{m+1}},
$$

where

$$
\begin{aligned}
& a=\left(1+K_{3}[\mathrm{O}]\right) / K_{\text {eff }} \xi, \\
& K_{\text {eff }}=K_{1} K_{2}\left[\mathrm{Mg}^{2+}\right], \\
& b=1+1 / K_{2}\left[\mathrm{Mg}^{2+}\right], \\
& c=K_{4} \xi^{m} .
\end{aligned}
$$


At high $p_{\mathrm{CO}_{2}}$, beyond an optimum temperature $\left(T_{\text {opt }}\right)$ the activation quotient $g(T, p)$ abruptly decreases indicating that reaction (15) is highly endothermic, with $K_{4}$ increasing very fast with temperature. Reactions (12) and (13) are also endothermic, and they contribute to the initial rise in activation (for $T<T_{\text {opt }}$ ) through the terms $a$ and $b$ in (18).

The equilibrium constants $K_{1}$ and $K_{2}$ are known from experiment, and $\left[\mathrm{Mg}^{2+}\right]$ can be obtained from measured data on chloroplast.

\subsection{Production of glucose equivalent}

Equation (1) is valid for all temperature and a large range of pressure. The most remarkable aspect of this rate law is that all quantities except $K_{3}[\mathrm{O}], K_{4}, m$ and $\xi$ that occur in $g(T, p)$ are generally known from experiment. So, a direct comparison with the experimental data becomes possible. The molecularity $m$ can be determined from the shape of $R_{\text {glucose }}$ versus $p_{\mathrm{CO}_{2}}$ plot. For $K_{3}[\mathrm{O}]$ and $\xi$ relative values can be obtained from coefficients $a$ and $c$ in (18).

In literature, the rate of the glucose-equivalent production is normally expressed in terms of the rate of $\mathrm{CO}_{2}$ assimilation $\left(A_{\mathrm{CO}_{2}}\right)$ that is six times the former rate, that is, $A_{\mathrm{CO}_{2}}=6 R_{\text {glucose }}$. From here onwards we will use $A_{\mathrm{CO}_{2}}$ in place of $R_{\text {glucose }}$.

\section{Results and discussion}

\subsection{Choice of variables}

The $\mathrm{CO}_{2}$ assimilation rates at different pressures have been considered for two specific $C_{4}$ species, $P$. coloratum and $P$. antidotale (figure 2$)^{2}$ As the photo-

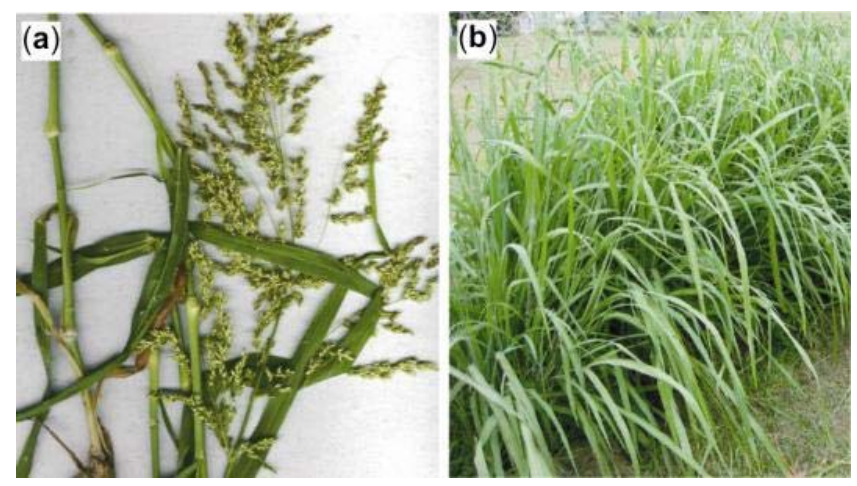

Figure 2. Plants under investigation: (a) P. antidotale, a typical Indian plant, (http://en.wikipedia.org/wiki/ Panacium_antidotale) and (b) P. coloratum, a plant commonly found in Australia (with permission from BruceCook C DPI\&F, http://www.tropicalforges.info). chemical efficiency for these two plants are not available, we have used the experimental average of photochemical efficiency values for $\mathrm{C}_{4}$ plants from. ${ }^{13}$ The volume of thylakoid lumen for a general higher plant leaf is estimated to be $0.0012 \mathrm{Lm}^{-2}{ }^{13}$ The ratio $[\mathrm{G} 3 \mathrm{P}] /\left[\mathrm{P}_{\mathrm{i}}\right]^{2}$ and the concentration reaction quotient $Q$ are the other experimental data which we have used in this work. All the data selected are for $\mathrm{C}_{4}$ plants or for a general leaf.

The plant cell is extensively compartmentalized. Compartmentation controls metabolism as well as transport. For example, the allocation of triose phosphates is largely controlled by the respective concentrations of G3P and $P_{1}$ in the stroma and in the cytosol. The conversion of G3P to sucrose and starch depends heavily on the quoted $\mathrm{P}_{\mathrm{i}}$ concentrations, which are constantly changing, let alone the vacuolar $P_{i}$ concentration. Even the total $P_{i}$ concentration changes from one species to another, and depends strongly on the physiological conditions such as soil, tissue, development stage, etc. Because of these reasons, we have adopted the average global (leaf) concentration of $\mathrm{P}_{\mathrm{i}}{ }^{2-}(100 \mathrm{mM})$ as well as the average global leaf concentration of G3P $(0.032 \mathrm{mM}) .{ }^{13}$ This gives the ratio $\left([\mathrm{G} 3 \mathrm{P}] /\left[\mathrm{P}_{\mathrm{i}}{ }^{2-}\right]^{2}\right)_{\text {leaf }}$ as approximately equal to 0.0032 in molar unit. The concentration values are correct only through two digits. This leaves a large margin of error.

We have used the relation $\Delta G_{\mathrm{E}}^{\mathrm{S}}=\Delta G^{0}-\Delta G^{\mathrm{S}}=-\mathrm{RT}$ $\ln Q_{\mathrm{G} 3 \mathrm{P} \rightarrow \mathrm{Glc}-6-\mathrm{P}}{ }^{2-}$. The quantity $\Delta G_{\mathrm{E}}^{\mathrm{S}}$ is estimated to be about $-2.5 \mathrm{kcal} \mathrm{mol}^{-1}$ by considering the relevant steps as discussed in table 4 of ref. 16 and the activity of water in vivo. ${ }^{9 b, 9 d, 16}$ See table 1 . Previously, we found that the value of $-2.55 \mathrm{kcal} \mathrm{mol}^{-1}$ accounts for about $80 \%$ conversion of G3P into glucoseequivalents in average $\mathrm{C}_{4}$ plants. ${ }^{9 \mathrm{a}}$ Therefore, we have retained the same value.

The equilibrium constants $K_{1}$ and $\mathrm{K}_{2}$ were determined by Laing et al, ${ }^{15} K_{1}=1.0989 \times 10^{4} \mathrm{M}^{-1}$ and $K_{2}=684.21 \mathrm{M}^{-1}$. P. antidotale and $P$. coloratum have $\mathrm{Mg}^{2+}$ ions to the extent of $0.49 \%$ and $0.67 \%$ of dry mass. ${ }^{17}$ The dry mass for a general leaf is about $0.04 \mathrm{Kg} \mathrm{m}^{-2}$ and the average leaf volume is $0 \cdot 3 \mathrm{~L} \mathrm{~m}^{-2},{ }^{13}$ and the same data can be adopted for $\mathrm{C}_{4}$ plants. The average number of chlorophyll is $5.6 \times 10^{-4} \mathrm{M} \mathrm{m}^{-2}$, accounting for about $0.00187 \mathrm{M}$ as the concentration of 'bound' $\mathrm{Mg}^{2+}$. Therefore, the concentration of extra-chlorophyll $\mathrm{Mg}^{2+}$ ion is $0.0253 \mathrm{M}$ in P. antidotale and $0.0354 \mathrm{M}$ in P. coloratum.

The rubisco activation quotient $g(T, p)$ varies in different species. It is known to vary even for the 
Table 1. Free energy changes in $\mathrm{kcal} \mathrm{mol}^{-1}$ of the relevant steps for the enzymatic conversion of G3P to Glc-6-P, from ref 16 . The quantity $\Delta G^{\mathrm{S}}$ is the free energy change at experimental condition and $\Delta G^{0}$ is the corresponding standard free energy change.

\begin{tabular}{|c|c|c|c|}
\hline Reactions & $\Delta G^{0}$ & $\Delta G^{\mathrm{S}}$ & $\Delta G^{0}-\Delta G^{\mathrm{S}}$ \\
\hline Glyceraldehyde-3- $\mathrm{P}^{2-} \rightarrow$ dihydroxyacetone- $\mathrm{P}^{2-}$ & -1.8 & $-0 \cdot 2$ & $-1 \cdot 6$ \\
\hline Glyceraldehyde $-3-\mathrm{P}^{2-}+$ dihydroxyacetone $-\mathrm{P}^{2-} \rightarrow$ Fru-1,6- $-\mathrm{P}_{2}^{4-}$ & $-5 \cdot 2$ & $-0 \cdot 4$ & $-4 \cdot 8$ \\
\hline Fru-1,6- $\mathrm{P}_{2}^{4-}+\mathrm{H}_{2} \mathrm{O} \rightarrow$ Fru-6- $\mathrm{P}^{2-}+\mathrm{P}_{\mathrm{i}}^{2-}$ & $-3 \cdot 4$ & $-6 \cdot 5$ & $3 \cdot 1$ \\
\hline Fru-6- $\mathrm{P}^{2-} \rightarrow$ Glc-6- $\mathrm{P}^{2-}$ & $-0 \cdot 5$ & $-0 \cdot 3$ & $-0 \cdot 2$ \\
\hline$\Delta G_{\mathrm{E}}^{\mathrm{S}}$ & & & $-2 \cdot 5^{1}$ \\
\hline
\end{tabular}

${ }^{1}$ The activity of water is considered to be diminished in vivo, thereby increasing $\Delta G_{\mathrm{E}}^{\mathrm{S}}$ by about $1.0 \mathrm{kcal} \mathrm{mol}^{-1}$. 16

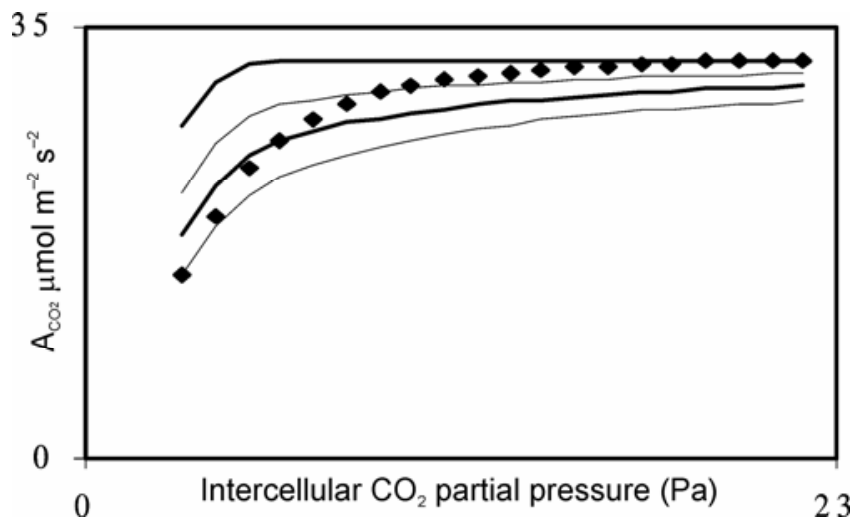

Figure 3. Plot of $A_{\mathrm{CO}_{2}}\left(=6 R_{\text {glucose }}\right)$ calculated with $m=$ 0 for $P$. antidotale. PPFD used is $940 \mu \mathrm{mol}$ quanta $\mathrm{m}^{-2} \mathrm{~s}^{-1}$. The plot shows that a $g(T, p)$ of the form $p /(a+b p)$ can never explain the experimental data (represented by $\bullet$ ). A similar plot is obtained for P. coloratum.

same plant in different seasons throughout the year. ${ }^{18}$ A detailed study on the temperature activation of rubisco for various plants by Crafts-Brandner and Salvucci reveals that in average the activation quotient varies in the range from $71 \%$ to $83 \%$ from $298 \mathrm{~K}$ to $308 \mathrm{~K}^{19}$

A discussion on PPFD is due here. It is known that excess light causes extensive photodamage. ${ }^{20}$ When the photon flux density is high, the excess energy is dissipated by non-photochemical quenching (NPQ). Ghannoum et al carried out a detailed investigation on the photochemical behaviour of both the species, $P$. antidotale and $P$. coloratum. ${ }^{2}$ We have taken the experimental data from their paper at PPFD $=940 \mu \mathrm{mol}$ quanta $\mathrm{m}^{-2} \mathrm{~s}^{-1}$. Whatever may be the effect of NPQ is inherent in their data.

The constant $\xi$ for the equilibrium between atmospheric $\mathrm{CO}_{2}$ and the $\mathrm{CO}_{2}$ dissolved in water is estimated to be $9.77 \times 10^{-3} \mathrm{M} \mathrm{Pa}^{-1}$ at STP. The estimation is based on the well-known solubility of
$\mathrm{CO}_{2}, 1.45 \mathrm{~g} \mathrm{~L}^{-1}$. This is several orders higher than the steady state $\xi$ for the cells of the two plant species under investigation. A possible reason for this is the presence of the bundle-sheath membrane. The steady-state ratio of the intracellular $\mathrm{CO}_{2}$ and the intercellular $\mathrm{CO}_{2}$ is controlled by diffusion through membrane which lowers the $\xi$ value by several orders.

Figure 3 shows that the observed $\mathrm{CO}_{2}$ assimilation rate can never be explained by an activation quotient of the form $p /(a+b p)$. This initiates the necessity of including the fourth step (denaturation of the activated enzyme) with $m \neq 0$. In fact, Crafts-Brandner et al have experimentally shown that activation of Rubisco decreases sharply after reaching the optimum temperature at around $35^{\circ} \mathrm{C} .{ }^{18,19}$ With the rise of temperature, the enzyme is denatured by heat. For $m=1$ one obtains a good fit with the experimental rates, both for $P$. antidotale and $P$. coloratum, when $b$ is fixed as $\left(1+1 / K_{2}\left[\mathrm{Mg}^{2+}\right]\right)$. We have used $\mathrm{K}_{2}=$ $684.21 \mathrm{M}^{-1}$ and $\left[\mathrm{Mg}^{+2}\right]=0.0253 \mathrm{M}$ and $0.0354 \mathrm{M}$ for $P$. antidotale and $P$. coloratum respectively. Also any change of $b$ from $\left(1+1 / K_{2}\left[\mathrm{Mg}^{2+}\right]\right)$ leads to a very strong digression from the experimental curves. The latter observation firmly establishes the existence of the two initial steps. These steps were originally proposed by King and Altman, ${ }^{10}$ Laing and Christeller, ${ }^{15}$ and Farquhar ${ }^{1 \mathrm{j}}$ from in vitro analyses. For $m>1$, the fitting worsens. We emphasize that the fitting with the observed data is extremely sensitive, and a good fit is obtained only with $m=1$ and $b=1+1 / K_{2}\left[\mathrm{Mg}^{2+}\right]$.

For $P$. antidotale and $P$. coloratum, $b$ equals 1.058 and 1.041 respectively. The least square fitting with $m=1$ yields the optimized parameters $a=$ $3.215, c=0.2672 \times 10^{-2}\left(\sigma^{2}=0.4133\right)$, and $a=2.666$, $c=1.042 \times 10^{-2}\left(\sigma^{2}=0.1074\right)$, for $P$. antidotale and $P$. coloratum respectively. The corresponding plots 
are given in figures 4 and 5. If we neglect inhibition (Step 3), we get $\mathrm{K}_{4}=1.645 \times 10^{3} \mathrm{M}^{-1}$ and $\xi_{\text {p.anti }}=$ $1.624 \times 10^{-6} \mathrm{MPa}^{-1}$ for $P$. antidotale and $K_{4}=$ $7.395 \times 10^{3} \mathrm{M}^{-1}$ and $\xi_{\text {p.col }}=1.409 \times 10^{-6} \mathrm{MPa}^{-1}$ for $P$. coloratum. Thus $K_{4}$ is of the order of $10^{3} \mathrm{M}^{-1}$, and $\xi$ is of the order of $10^{-6} \mathrm{MPa}^{-1}$, that is, the order of the Bunsen absorption coefficient of $\mathrm{CO}_{2}$ in water at $30^{\circ} \mathrm{C}$ which is about $0.7 \times 10^{-6} \mathrm{MPa}^{-1} .^{21}$ The quantity $\mathrm{K}_{\text {eff }} \xi$ is a constant of the order of unity in $\mathrm{Pa}^{-1}$ unit.

However, $K_{4}$ is an equilibrium constant that should remain same for both the species, and it is impossible to account for different $a c$ products without involving the third step (inhibition). It is well

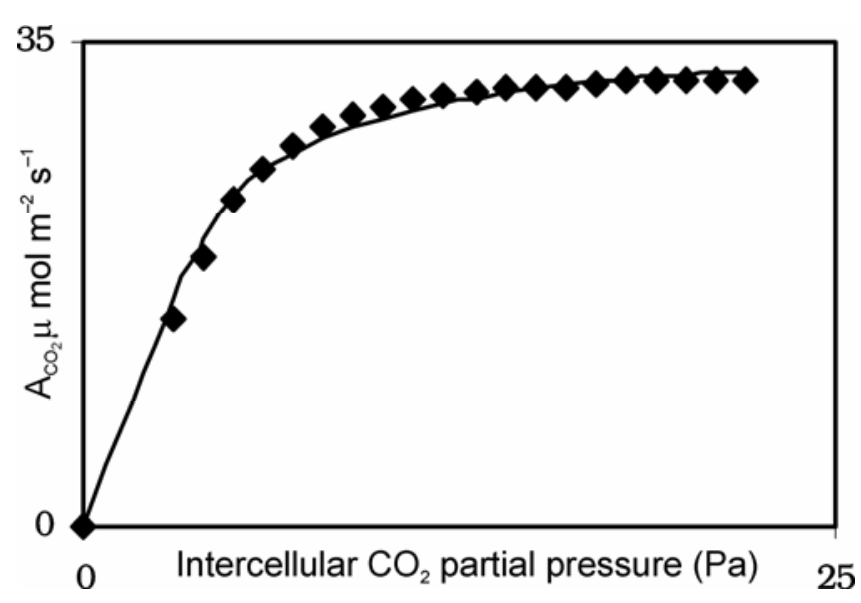

Figure 4. $A_{\mathrm{CO}_{2}}\left(=6 R_{\text {glucose }}\right)$ versus intercellular $\mathrm{CO}_{2}$ pressure for $P$. antidotale at $\mathrm{PPFD}=940 \mu \mathrm{mol}$ quanta $\mathrm{m}^{-2} \mathrm{~s}^{-1}$ and $T=303 \cdot 15 \mathrm{~K}$. The solid line is the theoritically calculated plot (this work), and the dots are the experimental data points from (Ghannoum et al 1998).

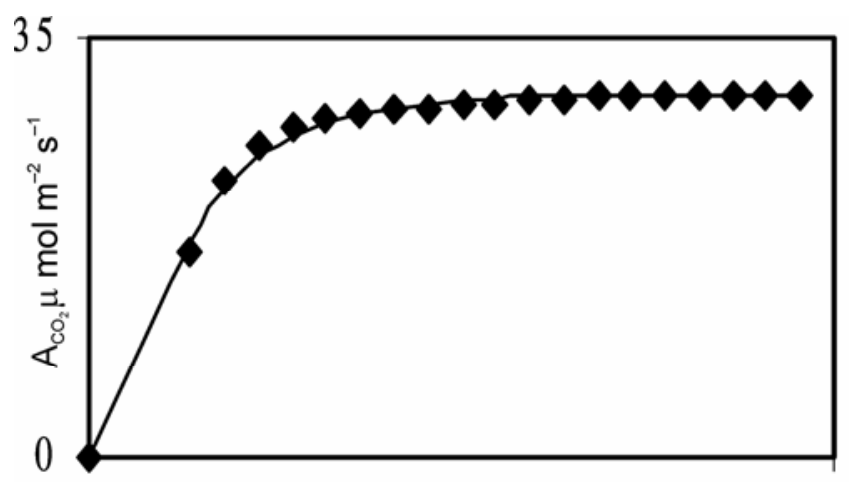

0 Intercellular $\mathrm{CO}_{2}$ partial pressure $(\mathrm{Pa})$

Figure 5. $A_{\mathrm{CO}_{2}}\left(=6 R_{\text {glucose }}\right)$ versus intercellular $\mathrm{CO}_{2}$ pressure for $P$. coloratum at $\mathrm{PPFD}=940 \mu \mathrm{mol}$ quanta $\mathrm{m}^{-2} \mathrm{~s}^{-1}$ and $\mathrm{T}=303 \cdot 15 \mathrm{~K}$. The solid line is the theoritically calculated plot (this work), and the dots are the experimental data points from (Ghannoum et al 1998). established that Rubisco is subject to competitive inhibition by $\mathrm{O}_{2}{ }^{22}$ When all the four steps are taken into consideration, the $c$ values show $\xi_{\text {p.anti }} / \xi_{\text {p.col }}=$ $0 \cdot 26$. In $P$. antidotale the steady state concentration of $\mathrm{CO}_{2}$ is about $70 \%$ less than that of $P$. coloratum. It can be easily shown that from the $a$ values one gets that ratio $\left(1+K_{3}[\mathrm{O}]_{\text {p.anti }}\right) /\left(1+K_{3}[\mathrm{O}]_{\text {p.col }}\right)=0 \cdot 31$. Thus the inhibitor in the $P$. antidotale is also about $70 \%$ less. This makes the net $\mathrm{CO}_{2}$ assimilation rate in $P$. coloratum comparable with that of $P$. antidotale in spite of the lower steady state concentration.

\section{Conclusion}

In this work, we have derived expressions for (i) the photochemical efficiency, (ii) the activation quotient of enzyme, and (iii) the rate of glucose-equivalent production in $\mathrm{C}_{4}$ plants. These expressions contain the explicit pressure dependence of the respective quantities. The activation process has been considered along with inhibition of the inactive enzyme and denaturation of the activated form, and the best activation quotient is realized in the form of (18) with $m=1$. Finally, we have obtained a pressure and temperature-dependent expression for the rate of glucose-equivalent production. To the best of our knowledge, this is the first time an analytical expression is derived for the pressure activation quotient of rubisco. The final rate equation is, of course, based on the theory ${ }^{23}$ and numerical simulation ${ }^{9 \mathrm{c}}$ of exciton dynamics on thylakoid membrane to find the rate of NADPH production. It also relies on the seven groups of biosynthetic reactions which we considered in our previous work. ${ }^{9 \mathrm{a}, \mathrm{b}}$

\section{Acknowledgements}

AP gratefully acknowledges the financial support from the Council of Scientific and Industrial Research (CSIR). Authors thank Bruce Cook for giving permission for reproduction of the image of $P$. coloratum in figure 2.

\section{References}

1. (a) Fleming G R and Scholes G D 2004 Nature 431 256; (b) Papadakis I A, Kotzabasis K and Lika K 2005 Biochim. Biophys. Acta 1708 250; (c) Holt N E, Zigmantas D, Valkunas L, Li Xiao-P, Niyogi K K and Fleming G R 2005 Science 307 433; (d) Brixner 
T, Stenger J, Vaswani H M, Cho M, Blankenship R E and Fleming G R 2005 Nature 434 625; (e) Farquhar G D 1998 Symposia of the Society for Experimental Biology 42 395; (f) Schöffl F, Prandl R and Reindl A 1998 Plant Physiol. 117 1135; (g) Sage R F 1990 Plant Physiol. 94 1728; (h) Salvucci M E and CraftsBrandner S J 2004 Physiol. Planta 120 179; 2004 Physiol. Planta 122 513; 2004 Plant, Cell and Environment 34 1460; (i) Gross L J, Kirschbaum M U F and Pearcy R W 1991 Plant, Cell and Environment 14 881; (j) Farquhar G D 1979 Arch. Biochem. Biophys. 193 456; (k) Farquhar G D 1983 Aust. J. Plant Physiol. 10 205; (1) Ghannoum O and Conroy J P 1998 Aust. J. Plant Physiol. 25 627; (m) Hattersley P W 1982 Aust. J. Plant Physiol. 9 139; (n) Hattersley P W and Watson L 1982 Diversification of photosynthesis (Cambridge: Cambridge University Press); (o) Hatch M D 1987 Biochim. Biophys. Acta 895 81; (p) Hatch M D, Agostino A and Jenkins C L D 1995 Plant Physiol. 108173

2. (a) Ghannoum O, Siebke K, Von Caemmerer S and Conroy J P 1998 Plant, Cell and Environ. 21 1123; (b) Ghannoum O, Von Caemmerer S, Ziska L H and Conroy J P 2000 Plant, Cell and Environ. 23931

3. (a) Wong S C 1979 Oecologia 44 68; (b) Morgan J A, Hunt H W, Monz C A and Le Cain D R 1994 Plant, Cell and Environ. 17 1023; (c) Le Cain D R and Morgan J A 1998 Physiol. Plant. 102 297; (d) Watling J R and Press M C 1997 Plant, Cell and Environ. 20 1292; (e) Ziska L H and Bunce J A 1997 Photosynth. Res. 54 199; (f) Ziska L H and Bunce J A 1999 Aust. J. Plant Physiol. 26 71; (g) Ziska L H, Sicher R C and Bunce J A 1999 Physiol. Plant. 105 74; (h) Wand S J E, Midgley G F, Jones M H and Curtis P S 1999 Global Change Biol. 5 723; (i) CraftsBrandner S J and Salvucci M E 2004 Field Crops Res. 9075

4. (a) Berry J A and Farquhar G D 1977 Proceedings of the 4th International Congress on Photosynthesis (Reading, London: The Biochemical Society) 1978; p 119; (b) Farquhar G D, Caemmerer S and Berry J A 1980 Planta 149 78; (c) Caemmerer S and Farquhar G D 1981 Planta 153 376; (d) Farquhar G D and Sharkey T D 1982 Annu. Rev. Plant. Physiol. 33 317; (e) Farquhar G D, Von Caemmerer S and Berry J A 2001 Plant Physiol. 125 42; (f) Hahn B D 1987 Ann. Bot. 60157

5. Harley P C, Weber J A and Gates D M 1985 Planta 165249
6. (a) Tenhunen J D, Weber J A, Yocum C S and Gates D M 1976 Oecologia 26 101; (b) Tenhunen J D, Weber J A, Filipek L H and Gates D M 1977 Oecologia 30 189; (c) Tenhunen J D, Meyer A, Lange O L and Gates D M 1980 Oecologia 45147

7. (a) $\mathrm{Vu} \mathrm{C} \mathrm{V}$, Crafts-Brandner S J and Salvucci M E 2004 Plant Sci. 171 123; (b) Vu C V, Allen L H Jr and Bowes G 1983 Plant Physiol. 73 729; (c) Mate J C, Caemmerer S, Evans J R, Hudson G S and Andrews T 1996 Planta 198 604; (d) Vu C V, Allen L H Jr and Russ W G 2006 Plant Sci. 171123

8. (a) Portis A R Jr, Salvucci M E and Ogren W L 1986 Plant Physiol. 82 967; (b) Cen Y-P and Sage R F 2005 Plant Physiol. 139979

9. (a) Mehta N, Panda A, Sengupta S and Datta S N 2006 J. Phys. Chem. B110 10951; Mehta N, Panda A, Sengupta S and Datta S N 2006 J. Phys. Chem. B110 14524; (b) Mehta N, Panda A, Roy A S and Datta S N 2007 J. Phys. Chem. B111 919; (c) Panda A and Datta S N 2005 Int. J. Quant. Chem. 105 84; (d) Panda A and Datta S N 2007 J. Chem. Sci. 119449

10. King E L and Altman C 1956 J. Phys. Chem. 601375

11. Leegood R C, Adcock M D, Doncaster H D and Hill R 1989 Philos. Trans. R. Soc. Lond. B 323339

12. Laisk A and Edwards G E 2000 Photosynthetic Res. 66199

13. Lawlor D W 1987 Photosynthesis metabolism, control and physiology (London: ELBS)

14. (a) Furbank R T and Hatch M D 1987 Plant Physiol. 85 958; (b) Furbank R T, Jenkins C L D and Hatch M D 1989 Plant Physiol. 91 1364; (c) Jenkins C L D, Furbank R T and Hatch M D 1989 Plant Physiol. 91 1374

15. Laing W A and Christeller J T 1976 Biochem. J. 159 563

16. Bassham J A and Krause G H 1969 Biochim. Biophys. Acta 189207

17. Tomar O S, Minhas P S, Sharma V K and Gupta R K 2003 J. Arid Env. 55533

18. Crafts-Brandner S J and Law R D 2000 Planta 21267

19. Crafts-Brandner S J and Salvucci M E 2000 PNAS 97 13430

20. Cogdell R J 2006 Trends in Plants Sci. 1159

21. Taiz L and Zeiger E 1991 Plant Physiol. (New York: The Benjamin Cummings Publishing Company Inc.) 1 st edn

22. Spreitzer R J and Salvucci M E 2002 Annu. Rev. Plant. Biol. 53449

23. Datta S N and Mallik B 1996 Int. J. Quant. Chem. 59147 